unsuccessfully, for an urban design approach based on New York itself. The book includes copious project documentation and diagrams, many published for the first time, providing thoughtful critiques and invaluable lessons in diagramming urban design ideas and relationships.

Peterson and Littenberg's work is among the most public of public urban design work, in that the overwhelming majority of their clients have been public agencies and groups, not private developers. As such, it probably can be said that their client is the city itself, and it is clear that New York is their "urban lab" and has taught them quite a bit. One project that emerges from the "lab" is an interesting critique of the recent Hudson Yards project, a massive development on the west side of Manhattan. In the "space vs anti-space" theory, Hudson Yards is clearly an example of the latter, missing most of the lessons to be gained from the spectacular urbanism of places like Rockefeller Center. Peterson and Littenberg show in clear and simple ways how a few moves could have transformed the entire project from what is a suburban layout of towers in a field to a richer and more emphatic engagement with the city. Through lessons learned studying the relationship of the Manhattan skyscraper to its urban block, they demonstrate how to engage a tower with a base and define a street wall. Such lessons would have immeasurably improved the entire project.

The book culminates in what is arguably the most impactful of Peterson and Littenberg's insights and contributions, a chapter devoted to "urban fabric," which demonstrates in simple and clear diagrams the relationship between the spatial elements of the city - parks, streets, plazas - to its solid elements, such as buildings and city blocks. The didactic nature of this chapter, an instructive distillation of the relationship between the building/ block and the role of public space in the making of the city, is the basis of their practice and insights on urban form. It is illustrated with well-chosen examples of the theory, and does as good a job of illustrating how good city fabric is made as any I've seen. I suppose one could have started the book with this section as the basis of their approach and followed with project examples, but as architects educated in the era of modernism, it is understandable that identifying Miesian theory and "anti-space" as the culprit in poor urban design is an essential first step. To provide a solution, one must have a clear diagnosis of the problem.

Overall, a terrific argument, set of projects and lessons learned. Space \& Anti-Space should be part of every architect's bookshelf.

Steven Peterson and Barbara

Littenberg

Space \& Anti-Space: The Fabric of Place, City and Architecture

ORO Editions, 2020

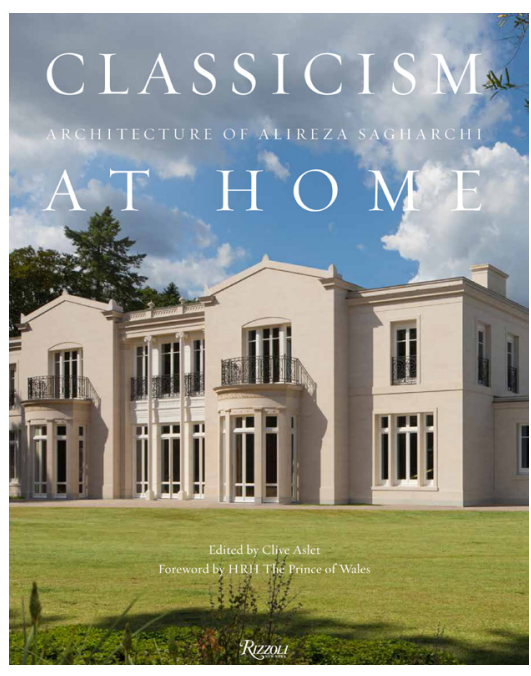

\section{Toward the Beautiful and Durable}

Hacia lo bello y lo duradero

Rumo ao belo e duradouro

\section{Thomas Norman Rajkovich}

In Classicism at Home: Architecture of Alireza Sagharchi, historian and author Clive Aslet establishes the biographical and intellectual backdrop for the work of this masterful composer-architect, who has created places of truly remarkable beauty in diverse contexts around the world.

\begin{abstract}
Alireza Sagharchi's inventive creativity, emerging from his intimate knowledge of the principles of classical architecture and local building traditions, allows him to design structures which "speak" the language of their specific location and culture.
\end{abstract}

These buildings are clear in their organization, elegant and appropriate in their proportion and material palette, informed by and complementary to their surroundings, and memorable in composition. As HRH, Prince Charles notes in the foreword, the architecture is meticulous in every respect.

They are, equally, places of great personality and character - gracious 
settings for both the quotidian and exceptional aspects of human life. This is an architecture at once scholarly and humane, made all the more resonant by the subtle mark of those craftspeople who contribute their essential handwork, under his guidance, during the course of construction.

In the completed projects there is a unity - a seamless unity - between Sagharchi's creative vision and its physical realization, what the Renaissance architect and theorist Leon Battista Alberti called the Art of Building, wherein ideas are translated into the material world.

In our visually cacophonous age, it requires great courage to undertake such work, in part because the profession has marginalized the classical and premiated the abstract and the invasive.

His confident and agile understanding of the classical language, its tectonic nature and its regional and global inflections, his deep study of vernacular methods of construction and craft technique, his recognition of the wisdom of designing buildings in ensemble, and his embrace of the richness of unique cultures, are brought to bear on contemporary projects, with a strident and optimistic conviction that beauty truly matters.

And, indeed, beauty triumphs brilliantly in these projects, providing a compelling demonstration that architecture today can stand on the shoulders of those who came before us, offering continuity with the best of our built heritage, celebrating the human condition, and creating, once again, works of surpassing durability, utility and delight.

Alireza Sagharchi and his collaborators in the Stanhope Gate studio inspire us with these buildings.

They lift our spirits with their poetic grace.

\section{Clive Aslet (ed.)}

Classicism at Home: Architecture of

Alireza Sagharchi

Rizzoli, 2020

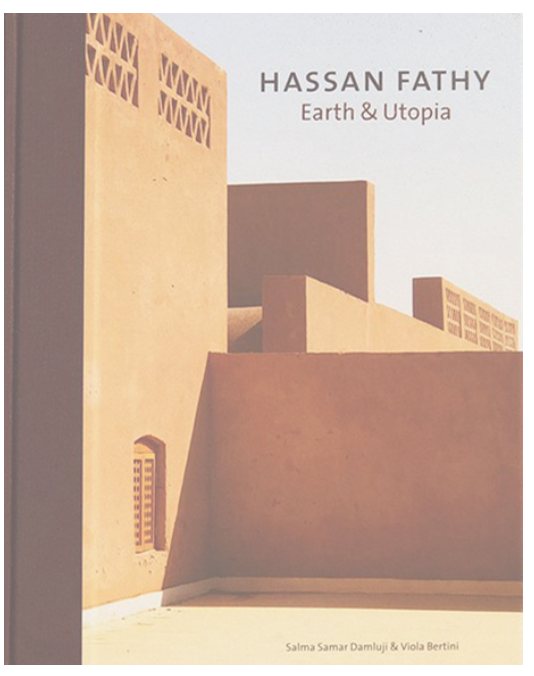

This new book is further enriched by Salma Samar Damulji's close contact with and deep knowledge of Hassan Fathy's lifetime efforts, concerns and stands and by the combination of her own studies of his work with those of Viola Bertini.

It provides more detailed information on his works, including not only insightful analysis, but also beautiful drawings, plans and pictures which were previously unknown or difficult to find. But beyond that, it allows one to understand Hassan Bey, as he was commonly called according to Salma Samar, within his own context: the core of his ideas, the cataclysmic changes in the urban and rural environments he witnessed, his quest for the vernacular architecture of Nubia, his collaboration with contemporary colleagues such as Constantinos Doxiadis, and his steady fight to save traditional crafts and an entire culture which was, and still is, seriously threatened.

Some of Hassan Fathy's writings are published here in English for the first time, and several interviews shed light on the way he designed, taught and lived, inextricably connected aspects in his case.

Among the many precious documents included in this volume is the text of a play he wrote in 1942 and edited with Salma Samar in 1984 in this current version: The Story of al Mashrabiyyah. In this story, Khalid, a sort of Fathy's alter ego, from a kind of Noah's Ark of Egyptian traditional crafts, tells us how much he hopes to "soon see all these mashrabiyyahs, windows, fountains and other treasures in their rightful places, in houses whose architectural magnificence they shall reflect", which he views as "the precious heritage of our forefathers".

Salma Samar Damluji and Viola Bertini

Hassan Fathy: Earth and Utopia

Laurence King, 2018
Fathy: Earth and Utopia, published by Laurence King in 2018. 